\section{International Scientific Journal Theoretical \& Applied Science}

p-ISSN: 2308-4944 (print) e-ISSN: 2409-0085 (online)

Year: $2018 \quad$ Issue: $01 \quad$ Volume: 57

Published: $30.01 .2018 \quad$ http://T-Science.org
Asli Khanguseyn Kazymova

Doctor of Philosophy in Economics, Senior lecturer of the department "Regulation of Economics" Azerbaijan State Economic University, Azerbaijan Republic

SECTION 19. Management. Marketing. Public administration.

\title{
THE STRATEGIC DIRECTIONS AND REALITIES OF DEVELOPMENT OF NON-PERFECT SECTORS OF THE ECONOMY OF AZERBAIJAN
}

Abstract: The problems of strategic directions and realities of development of non-oil sectors of the Azerbaijani economy in the current conditions are examined in the article. The main goals and tasks of development of the national economy of Azerbaijan in the framework of strategic road maps are analyzed. The prospects and realities of economic development in the context of strategic road maps are revealed. The potential for increasing the competitiveness of the national economy, export competition, increasing export potential and increasing the attraction of foreign direct investment are estimated. The prospects of implementing the economic development strategy until 2020 and the strategy of economic development for the long-term period by 2025 are considered. The scientific views on the problems of strategic direction and realities for the development of non-oil sectors of the Azerbaijani economy are generalized.

Key words: Azerbaijan, non-oil sector, strategic directions of development of non-oil sectors, realities of development of non-oil sectors of economy, main goals and tasks of strategic road maps.

Language: Russian

Citation: Kazymova AK (2018) THE STRATEGIC DIRECTIONS AND REALITIES OF DEVELOPMENT OF NON-PERFECT SECTORS OF THE ECONOMY OF AZERBAIJAN. ISJ Theoretical \& Applied Science, 01 (57): $220-226$.

Soi: $\underline{\text { http://s-o-i.org/1.1/TAS-01-57-36 Doi: crostef https://dx.doi.org/10.15863/TAS.2018.01.57.36 }}$

\section{СТРАТЕГИЧЕСКИЕ НАПРАВЛЕНИЯ И РЕАЛИИ РАЗВИТИЯ НЕНЕФТЯНЫХ СЕКТОРОВ ЭКОНОМИКИ АЗЕРБАЙДЖАНА}

Аннотация: В статье исследованы проблемы стратегических направлений и реалий развития ненефтяных секторов экономики Азербайджана в нынешних условиях. Анализированы основные ичели и задачи развития национальной экономики Азербайджан в рамках стратегических дорожных карт. Раскрыты перспективы и реалии развития экономики в контексте стратегических дорожных карт. Оченены потенциал повышения конкурентоспособности национальной экономики, конкуренция экспорта, увеличение экспортного потенциала и расширение привлечения прямых иностранных инвестиций. Рассмотрены перспективы реализации стратегии экономического развития до 2020 года и стратегия экономического развития на долгосрочный период к 2025 году. Обобщены научные взгляды по проблемам стратегического направления и реалий по развитию ненефтяных секторов экономики Азербайджана.

Ключевые слова: Азербайджан, ненефтяной сектор, стратегические направления развития ненефтяных секторов, реалии развития ненефтяных секторов экономики, основнье иели и задачи стратегических дорожных карт.

\section{Introduction}

В последние годы проводятся исторические и широкомасштабные работы по обеспечению устойчивости и прочности национальной экономики Азербайджана, путем развития ненефтяных секторов экономики страны. Геостратегические и геоэкономические факторы развития национальной экономики дают возможность расширить сферу деятельности экономики страны за счет создания новых модернизированных секторов экономики, таких как, сектор информационно-коммуникационных технологий, туризма, а также интенсификации развития традиционных секторов экономики промышленной сферы - химии и нефтехимии, металлургии, сельскохозяйственного и аграрного 
производства, текстильной и пищевой промышленности и прочие.

\section{Materials and Methods}

Отметим, что Указ Президента Азербайджанской Республики об утверждении стратегических дорожных карт по национальной экономике и основным секторам экономики страны открыл новые возможности реализации стратегических целей и задач развития национальной экономики и формирования более модернизированной и усовершенствованной модели экономического развития [1]. Уже идет интенсивная реализация данной стратегии, создаются новые государственные и управленческие структуры, активно проводятся институциональные реформы, разрабатываются и применяются новые механизмы по поддержке сельскохозяйственного и аграрного сектора. Стимулируется ненефтяной экспорт и это дало серьезный толчок расширению объема и ассортимента экспорта за счет ненефтяных продукций и товаров. Более того, в рамках стратегических дорожных карт рассматривается интенсификация развития тех ненефтяных секторов экономики страны, которые способны максимально больше создать добавочную стоимость, способствовать открытию новых рабочих мест, повышению роста экономики и экспортного потенциала. Подобные подходы и механизмы и одновременно стратегические цели и задачи позволят существенно поднять конкурентоспособный уровень и объем экономики страны в ближайшей перспективе $[2 ; 3 ; 4 ; 5 ; 6 ; 7 ; 8 ; 9]$.

Отметим, что разработка и осуществление стратегических дорожных карт востребовано необходимостью решения глобальных проблем по модернизации и развитию национальной экономики страны в условиях роста глобальных экономических угроз и усиления негативных последствий нестабильности мирохозяйственных и экономических процессов в мире. В этих условиях одной из главных задач правительства Азербайджана является обеспечение максимальной минимизации зависимости национальной экономики от нефтяного фактора и ускорить развитие ненефтяных секторов путем привлечения иностранных инвесторов, высоких технологий. Так, до 2025 года предусматривается увеличение доли иностранных инвестиций в ненефтяной внутренне валовой продукции в пределах 4 \%. Для сравнения отметим, что данный показатель сейчас равен лишь 2,627 \%. Более того, намечается увеличение объема ненефтяного экспорта на душу населения страны, как минимум, к уровню 450 долл. США по отношению к нынешним 170 долл. США. [10]. Реализация дорожных карт поможет раскрыть потенциал отдельных ненефтяных секторов экономики страны путем интенсификации использования ресурсов регионов, рационализации производительных сил и рабочей силы, активизации региональных субъектов по формированию новых источников роста национальной экономики, развитию предпринимательства, улучшению инвестиционно-инновационной и бизнес-среды, в целом способствовать повышению устойчивости и прочности национальной экономики. Но для этого требуется взвесить все плюсы и минусы, позитивные и негативные факторы развития ненефтяных секторов экономики страны, дабы не создать трудности динамичности развития модели экономического развития страны с учетом его особенностей и исторических аспектов развития. В стране необходимо усилить инноватизацию национальной экономики, развивать рынок технологий и инноваций, финансовый рынок и рынок страхований, рынок ценных бумаг, рынок капитала, и тем самым создать более благоприятные условия развития бизнес-среды, поощрение иностранного капитала, привлекательный климата по привлечению иностранных инвестиций и прихода инвесторов в страну.

Отметим, что в стратегических дорожных картах вопросы и проблемы, связанные с реальностью развития ненефтяных секторов экономики страны определены на основе глубоких научно-экономических подходов с участием местных и иностранных экспертов. Рассмотрены объективные реалии развития ненефтяного сектора экономики страны с упором расширения их деятельности по созданию добавочной стоимости и конкурентоспособной продукции для повышения экспортного потенциала. Основные цели и задачи развития национальной экономики Азербайджана в рамках стратегических дорожных картах отражены на Рисунке 1. 


\begin{tabular}{|c|c|c|c|c|c|c|}
\hline Impact Factor: & $\begin{array}{l}\text { ISRA (India) } \\
\text { ISI (Dubai, UAE } \\
\text { GIF (Australia) } \\
\text { JIF }\end{array}$ & $\begin{array}{l}=1.344 \\
=0.829 \\
=0.564 \\
=1.500\end{array}$ & $\begin{array}{l}\text { SIS (USA) } \\
\text { PИНЦ (Russia) } \\
\text { ESJI (KZ) } \\
\text { SJIF (Morocco) }\end{array}$ & $\begin{array}{l}=0.912 \\
=0.207 \\
=4.102 \\
=\mathbf{2 . 0 3 1}\end{array}$ & $\begin{array}{l}\text { ICV (Poland) } \\
\text { PIF (India) } \\
\text { IBI (India) }\end{array}$ & $\begin{array}{l}=6.630 \\
=1.940 \\
=4.260\end{array}$ \\
\hline
\end{tabular}

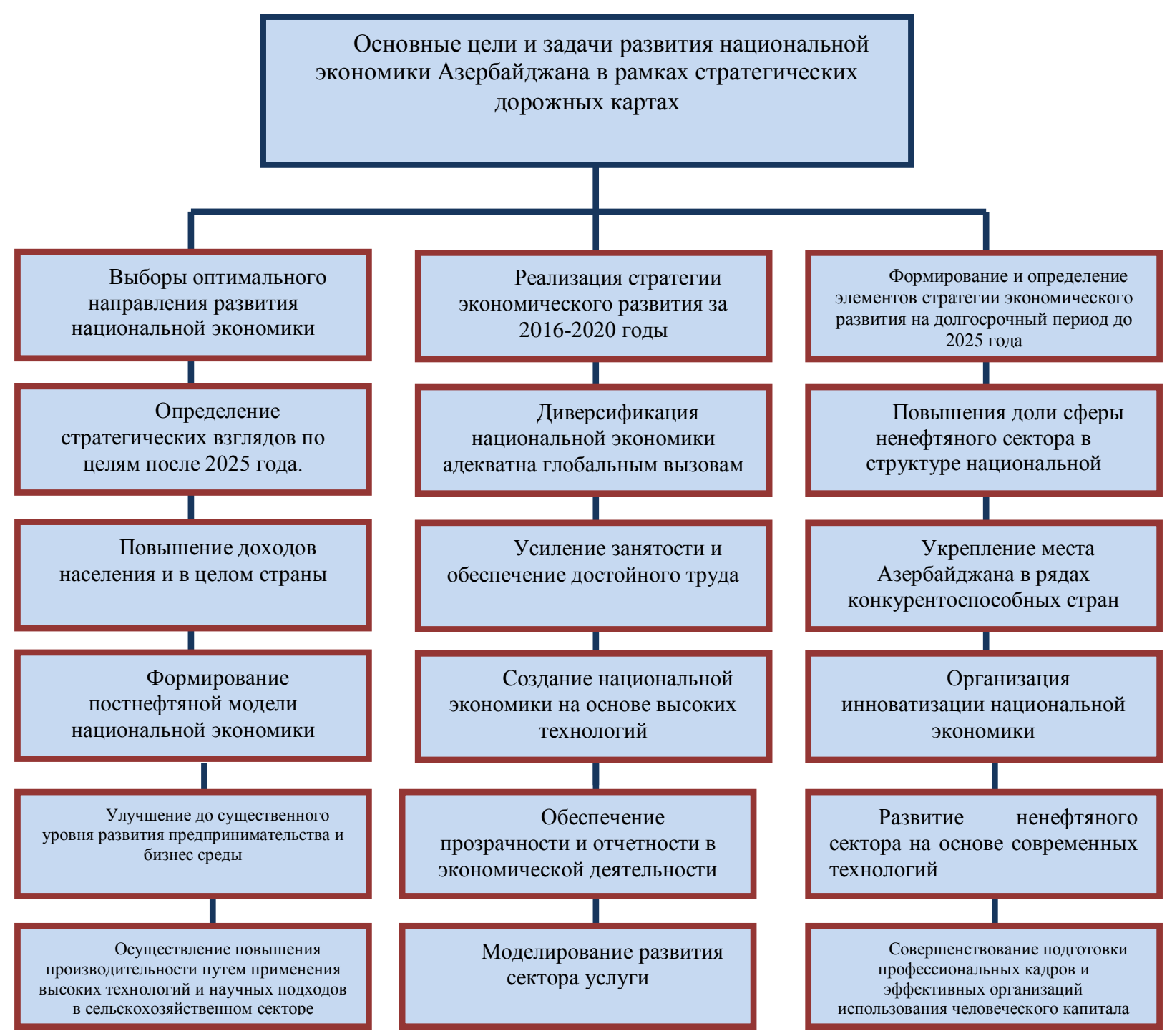

\section{Рисунок 1. Основные цели и задачи развития национальной экономики Азербайджана в рамках стратегических дорожных картах (подготовлено автором)}

Как видно, в рамках стратегических дорожных карт, в ближайшие 10-15 лет придется решить и осуществить немалые стратегические цели и задачи по модернизации, обновлению, совершенствованию механизмов развития национальной экономики Азербайджана, созданию новых перспективных и инклюзивных направлений развития с уклоном добавочной стоимости, определения новых и продуктивных источников роста экономики страны в контексте глобальных вызовов, обеспечения ускорения инноватизации, создания новых сфер экономики на базе высоких технологий, улучшения уровня предпринимательства и бизнес-среды с учетом обеспечения прозрачности и отчетности экономических сфер, соблюдения главных критерий усиления экономической безопасности страны и прочее.

На Рисунке 2 отражены обобщенные перспективы и реалии экономики Азербайджана в контексте стратегических дорожных карт, утвержденные Указом Президента Азербайджанской Республики от 6 декабря 2016 года. 


\begin{tabular}{l|lr|ll|ll} 
& ISRA (India) & $=\mathbf{1 . 3 4 4}$ & SIS (USA) & $=\mathbf{0 . 9 1 2}$ & ICV (Poland) & $=\mathbf{6 . 6 3 0}$ \\
Impact Factor: & ISI (Dubai, UAE) $=\mathbf{0 . 8 2 9}$ & PUHЦ (Russia) $=\mathbf{0 . 2 0 7}$ & PIF (India) & $=\mathbf{1 . 9 4 0}$ \\
& GIF (Australia) & $=\mathbf{0 . 5 6 4}$ & ESJI (KZ) & $=\mathbf{4 . 1 0 2}$ & IBI (India) & $=\mathbf{4 . 2 6 0}$ \\
& JIF & $=\mathbf{1 . 5 0 0}$ & SJIF (Morocco) & $=\mathbf{2 . 0 3 1}$ & & \\
\hline
\end{tabular}

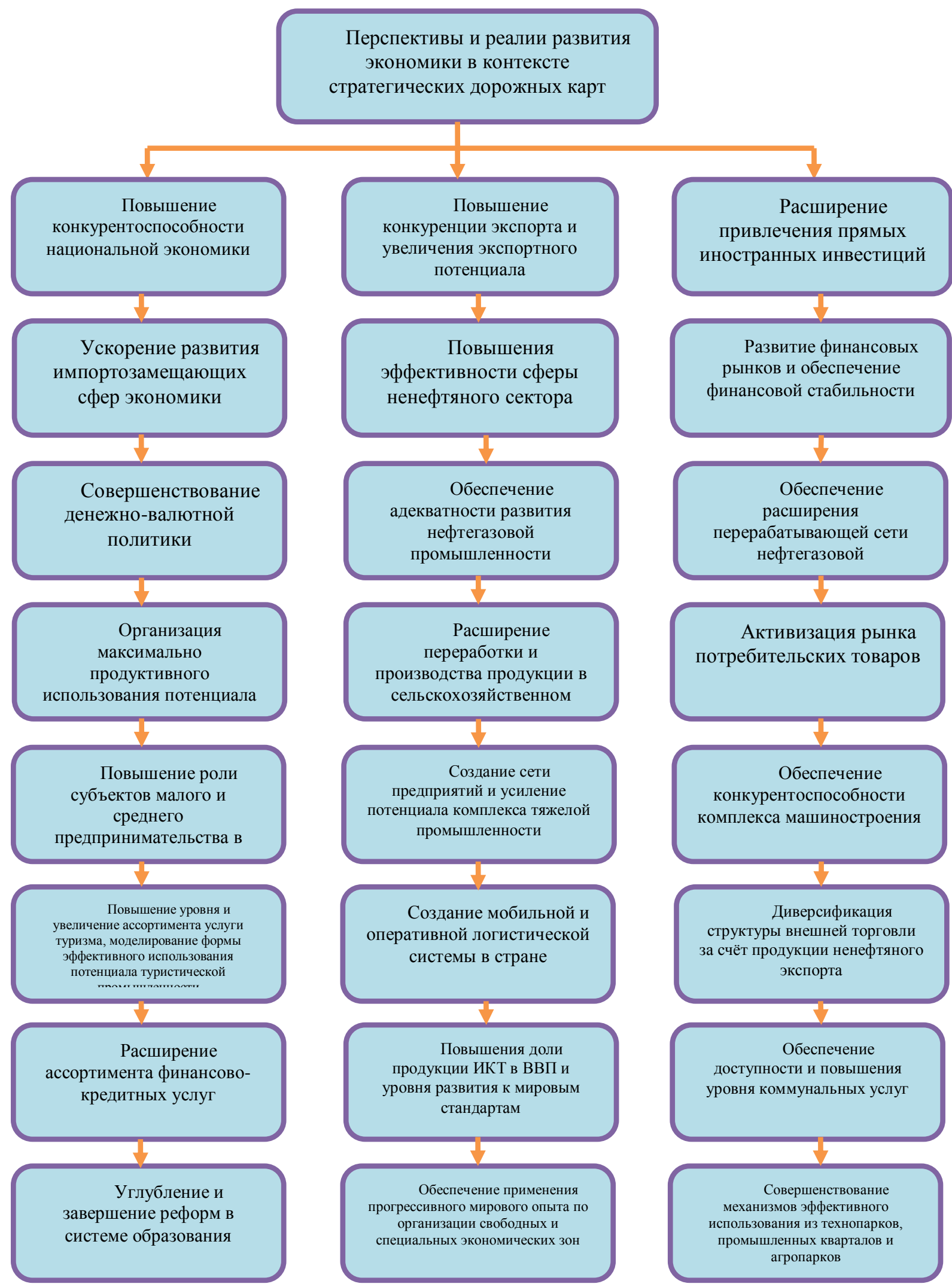

Рисунок 2. Перспективы и реалии развития экономики в контексте стратегических дорожных карт в Азербайджанской Республики (составлено автором). 
Отметим, что в рамках реализации основных целей и задач в контексте стратегических дорожных карт и использования существующего потенциала по повышению конкурентоспособности национальной экономики, конкуренции экспорта и увеличения экспортного потенциала, расширения привлечения прямых иностранных инвестиций в разные сферы ненефтяных секторов экономики страны уже проводятся полномасштабные и целенаправленные мероприятия, реформы, институциональные и структурные изменения. Особая работа проводиться по углубленному изучению резервов для роста национальной экономики и реализации существующих потенциалов отдельных сфер ненефтяных секторов экономики страны $[11 ; 12 ; 13]$. По мнению большинства специалистов, стратегические дорожные карты придадут серьезный стимул и толчок по переходу на новые фазы проводимых экономических реформ в Азербайджане [14]. Стоит подчеркнуть, что в подготовке стратегических дорожных карт участвовало до 400 местных и иностранных специалистов, ученых, представителей общественных и научных организаций. В общем, подготовлены и даны свыше 1000 письменных предложений по рассматриваемым проблемам в рамках стратегических дорожных карт [15]. В корне рассматриваемых механизмов и элементов развития разные сферы национальной экономики, в первую очередь ненефтяных сфер экономики страны рассматриваются более продуктивные и прогрессивные подходы, инструментарии. Кроме того, в рамках реализации стратегических дорожных карт прогнозируется активизация и рационализация использования природных ресурсов, внутренних и внешних факторов развития национальной экономики, особенно экспортно-ориентировочные сферы деятельности, усилиться рычаги экономической дипломатии страны по повышению эффективности внешнеэкономических связей с другими странами мира [16;17;18]. В рамках рассмотрения и определения стратегических целей и задач перспективных направлений развития национальной экономики Азербайджана и его отдельных сфер и в ближайшей и долгосрочной перспективе учтены особенности развития экономической системы и приоритеты модели экономического развития страны с учетом глобальных экономических вызовов и экономических угроз. Отрадно, что после принятия данного стратегического документа интенсивно осуществляется приведения к адекватности существующих разных программ экономического развития, законов, правил и порядок по разным направлениям деятельности экономической сферы страны, сбалансируется стабильность экономической системы с происходящими изменениями в мировых экономических пространствах. Большинство специалистов предполагает, что реализация стратегических дорожных карт существенно повысит эффективность проводимых экономических реформ по основным сектором экономики страны [19]. Например, руководитель отдела сотрудничества Бакинского представительство Евросоюза Жейрон Вилленс отмечает, что стратегическая дорожная карта принятия для реализация экономических реформ в Азербайджане обеспечит диверсификацию национальной экономики и окажет серьезный толчок развития ненефтяного сектора [20]. Кроме того, стратегия будет способствовать совершенствования механизма учета, усиления налоговой системы, повышения прозрачности налоговых и таможенных систем. В результате улучшиться уровень отчетности и прозрачности в разных сферах ненефтяного сектора экономики страны [21]. Прогнозируется, что реализация стратегической дорожной карты будет способствовать повышения экономической мощности и престижа Азербайджана не только в регионе и в международном масштабе. Ожидается существенное поднятие важности данной стратегии в эффективной модернизации экономической системы страны адекватно глобальным вызовом [22]. В тоже время, стратегические дорожные карты окажут положительное влияние на совершенствование системы управления разных сфер ненефтяного сектора. Эксперт по экономическим реформам Р. Гусейнов подчеркивает, что уже реализован ряд важных мероприятий в рамках стратегической дорожной карты по развитию экономики страны, улучшению инвестиционной и бизнес-среды, созданию благоприятных условий для предпринимателей, усилению государственной поддержки со сферами ненефтяного сектора, повышения потенциала ненефтяного экспорта и развития сферы деятельности по импортозамещению [23].

\section{Conclusion}

Таким образом, стратегические направления и реалии развития ненефтяных секторов экономики Азербайджана в нынешних условиях требуют в обязательном порядке учесть влияние глобальных экономических тенденций и трансформаций мирохозяйственной системы с учетом обеспечения национальных интересов и критерий экономической, безопасности страны. В этом случае, появится больше возможностей для интенсификации развития национальной экономики за счет инклюзивных сфер ненефтяного сектора путем повышения производительности, применения современной 
технологии, расширения конкурентоспособных экспортоориентированных продукций и т.д.

\section{References:}

1. (2016) Ukaz Prezidenta Azerbaydzhanskoy Respubliki ob utverzhdenii strategicheskikh dorozhnykh kart po natsional'noy ekonomike i osnovnym sektoram ekonomiki. Gorod Baku, 6 dekabrya 2016 god. Available: http://www.president.az. $\quad$ (Accessed: 10.01.2018).

2. (2018) V ramkakh strategicheskikh dorozhnykh kart opredeleny osnovnyye tseli po prioritetnym napravleniyam ekonomiki. Available: http://www.respublica-news.az. (Accessed: 10.01.2018).

3. (2018) Spetsial'nyy vypusk "UNEC Ekspert": "Strategicheskiye dorozhnyye karty". Available: http://edumap.az. (Accessed: 10.01.2018).

4. (2016) The Road Map of an Anti-Crisis Strategy in Azerbaijan. Center for Economic and Social Development (CESD). Baku, 2016.

5. (2018) Provedeno zasedaniye Sostav Prezidiuma NANA po obsuzhdeniyu «Strategicheskikh dorozhnykh kart po natsional'noy ekonomike i osnovnym sektoram ekonomiki». Available: http://www.science.gov.az/news/open/4226\#. (Accessed: 10.01.2018).

6. (2018) Strategicheskiye Dorozhnyye Karty: Budet obespecheno prisoyedineniye $\mathrm{k}$ mezhdunarodnym shlyuzam i budet povysheno skorost' mezhdunarodnykh kanalov po nyneshnemu sprosu. Available: http://economic.az. (Accessed: 10.01.2018).

7. (2018) Obsuzhdeny Strategicheskikh dorozhnykh kart po osnovnym sektoram natsional'noy ekonomiki. Available: http://economics.com. (Accessed: 10.01.2018).

8. (2018) Strategicheskiye dorozhnyye karty sygrayut rol' mayaka $\mathrm{v}$ ustoychivom razvitii strany. Available: http://www.ikisahil.az/?lang=aze\&page=4\&ne wsld $=56430$. (Accessed: 10.01.2018).

9. (2018) Strategicheskiye Dorozhnyye Karty: Novyy povorot $\mathrm{v}$ razvitii natsional'noy ekonomiki. Available: http://modern.az/az/news/12075\#gsc.tab=0. (Accessed: 10.01.2018).

10. (2018) Chto oznachayut dorozhnyye karty? Available: http://www.bbc.com/azeri/azerbaijan38301370. (Accessed: 10.01.2018).

11. Aliyev SH.T. (2016) Kontseptual'nyye napravleniya usileniya eksportnogo potentsiala $\mathrm{i}$ promyshlennogo sektora v Azerbaydzhane // Zhurnal «Ipyak Yolu», №04, 2016.-p.35-42.

12. Aliyev Sh.T., Sazmani N.E. (2017) The problems of diversification of Azerbaijan's export potential in modern condition //Journal «International scientific review». Boston, USA, №02-2017. -p. 41-45.

13. Aliyev SH.T. (2017) Puti povysheniya eksportnogo potentsiala $\mathrm{V}$ realizatsii strategicheskikh dorozhnykh kart V Azerbaydzhane // Zhurnal «Audit», № 1, 2017.p.60-66.

14. (2018) Prinyatiya strategicheskikh dorozhnykh kart tsel'yu realizatsii ekonomicheskikh reform v Azerbaydzhane budet sluzhit' v rasshirenii natsional'noy ekonomiki i dast tolchok v razvitii neneftyanogo sektora Available: https://news.milli.az/politics/578927.html. (Accessed: 10.01.2018).

15. (2018) Strategicheskaya dorozhnaya karta, podgotovlennoye do 400-kh ekspert Available: http://axar.az/news/gundem/126988.html. (Accessed: 10.01.2018).

16. Aliyev SH.T. (2017) Vazhnost' spetsial'nykh ekonomicheskikh zon $\mathrm{v}$ realizatsii strategicheskikh dorozhnykh kart v Azerbaydzhane// Zhurnal «Geostrategiya», Baku, №1, 2017., №01(37).-p.32-35.

17. Aliyev SH.T. (2017) Vazhnost' usileniya natsional'noy ekonomicheskoy diplomatii $\mathrm{V}$ intensifikatsii osushchestvleniya strategicheskoy dorozhnoy karty v Azerbaydzhane// Zhurnal «Audit» № 1, 2017.p.60-66.

18. Aliyev SH.T. (2017) Puti povysheniya eksportnogo potentsiala $\mathrm{v}$ realizatsii strategicheskikh dorozhnykh kart// Zhurnal «Geostrategiya», Baku, №03, 2017., №03(39).p.20-23.

19. (2018) Strategicheskiye dorozhnyye karty po ekonomiki obespechit effektivnosti reform $\mathrm{m}$ http://www.xalqqazeti.com/az/news/economy/7 8895 Available: (Accessed: 10.01.2018).

20. (2018) Strategicheskaya dorozhnaya karta prinyatiya dlya realizatsiya ekonomicheskikh 


\begin{tabular}{l|lr|ll|ll} 
& ISRA (India) & $=\mathbf{1 . 3 4 4}$ & SIS (USA) & $=\mathbf{0 . 9 1 2}$ & ICV (Poland) & $=\mathbf{6 . 6 3 0}$ \\
Impact Factor: & ISI (Dubai, UAE) $=\mathbf{0 . 8 2 9}$ & PUH (Russia) $=\mathbf{0 . 2 0 7}$ & PIF (India) & $=1.940$ \\
& GIF (Australia) & $=\mathbf{0 . 5 6 4}$ & ESJI (KZ) & $=4.102$ & IBI (India) & $=\mathbf{4 . 2 6 0}$ \\
& JIF & $=1.500$ & SJIF (Morocco) $=\mathbf{2 . 0 3 1}$ & & \\
\hline
\end{tabular}

reform $\mathrm{v}$ Azerbaydzhane obespechit diversifikatsiyu natsional'noy ekonomiki i okazhet ser'yeznyy tolchok razvitiya neneftyanogo sektora Available: http://news.milli.az/politics/578927.htmlm. (Accessed: 10.01.2018).

21. (2018) Strategicheskiye dorozhnyye karty ekonomiki Azerbaydzhana: Problemy otchetnosti i prozrachnosti. Available: http://www.unes.edu.az. $\quad$ (Accessed: 10.01.2018).
22. (2018) Utverzhdeno strategicheskiye dorozhnyye karty po natsional'noy ekonomike i osnovnym sektoram ekonomiki Available: http://metbuat.az. (Accessed: 10.01.2018).

23. Ramil' Guseyn (2017) Rol' strategicheskikh dorozhnykh kart $\mathrm{v}$ konkurentosposobnoy i ustoychivoy razvitii ekonomiki Azerbaydzhana// Zhurnal strategicheskogo analiza, 21 dekabrya 2017 goda. Available: http://stj.sam.az. (Accessed: 10.01.2018). 